\title{
COMPONENTES DE PRODUÇÃO E PRODUTIVIDADE DE CULTIVARES DE ALGODÃO (GOSSYPIUM HIRSUTUM) NO MUNICÍPIO DE CONFRESA - MATO GROSSO
}

\author{
PRODUCTION COMPONENTS OF COTTON CULTIVARS (GOSSYIUM \\ HIRSUTUM) IN THE MUNICIPALITY OF CONFRESA - MATO GROSSO
}

\author{
Matheus Candido Vilela ${ }^{1}$ (D), Danilo Nogueira dos $\operatorname{Anjos}^{2}$ (D), Yuri de Oliveira Castro ${ }^{3}$ (D), \\ Luciana Alves Martins ${ }^{4}$ (D)
}

Recebido em 12 de Outubro de 2020 | Aprovado em 17 de Dezembro de 2020

\section{RESUMO}

A cultura do algodão se apresenta como uma alternativa rentável para os produtores, entretanto é de difícil manejo, possuindo diversas problemáticas que interferem durante o ciclo da cultura. $\mathrm{O}$ uso de algumas estratégias como a escolha da cultivar mais adaptada para a região, poderá diminuir a probabilidade de perdas e erros ao final do ciclo da cultura. Este trabalho teve como objetivo avaliar adaptabilidade e produtividade de dez cultivares de algodão no município de Confresa - MT. O experimento foi conduzido a campo aberto, utilizando o delineamento inteiramente casualizados, na qual observou-se as seguintes variáveis: produtividade, estande, altura, número de capulhos, número de aborto por planta e números de nó. Os resultados foram submetidos pelo software estatístico SISVAR e comparadas pelo teste de Scott-Knott $(p<0,5)$. A cultivar que se destacou em termos de produção de pluma foi a IMA 5801 B2RF.

Palavras-chave: Cotonicultura; Produtividade; Adaptabilidade; Variabilidade Genética

\begin{abstract}
The cotton culture presents itself as a profitable alternative for the producers, however it is difficult to handle, having several problems that interfere during the culture cycle. The use of some strategies, such as the choice of the most suitable cultivar for the region, may decrease the probability of losses and errors at the end of the crop cycle. This work aimed to evaluate adaptability and productivity of ten cotton cultivars in the municipality of Confresa - MT. The experiment was conducted in an open field, using a completely randomized design, in which the following variables were observed: productivity, stand, height, number of bolls, number of abortions per plant and number of knots. The results were submitted using the SISVAR statistical software and compared using the Scott-Knott test ( $\mathrm{p}<0.5)$. The cultivar that stood out in terms of plume production was IMA 5801 B2RF.
\end{abstract}

Keywords: Cotton culture; Productivity; Adaptability; Genetic variability.

\footnotetext{
${ }^{1}$ Estudante de Agronomia na Instituição IFMT, Confresa, Mato Grosso, Brasil. Endereço para correspondência: Rua Mn4., SN, Morada Nova, Confresa, Mato Groso, Brasil, CEP: 78652-000. E-mail: matheusagrovilela@gmail.com.

${ }^{2}$ Doutor em Fitotecnia pela Instituição UESB. Professor na Instituição IFMT, Confresa, Mato Grosso, Brasil para correspondência: Rua Mn2., 351, Morada Nova, Confresa, Mato Grosso, Brasil, CEP 78652-000. E-mail: danilo.anjos@cfs.ifmt.edu.br.

${ }^{3}$ Mestre em Agronomia pela Instituição UFG. Professor na Instituição IFMT, Confresa, Mato Grosso, Brasil. Endereço para correspondência: Av. Vilmar Fernandes., 300, Confresa, Mato Grosso, Brasil, CEP: 78652-000. E-mail: yuri.castro@cfs.ifmt.edu.br.

${ }^{4}$ Eng. Agrônoma na empresa Xingu Pesquisa e Consultoria, Confresa, Mato Grosso, Brasil. Endereço para correspondência: Rua Devani, 221, Babinski, Confresa, Mato Grosso, Brasil, CEP: 78652-000. E-mail: luciana@xinguconsultoria.com.br
} 


\section{Introdução}

O interesse dos agricultores pelo cultivo do algodão na região nordeste do estado do Mato Grosso (Araguaia-Xingu) está relacionado ao seu alto valor econômico e por ser uma das culturas anuais mais rentáveis no meio agrícola. Contudo ela exige grande conhecimento técnico, pois seu manejo é uma das principais problemáticas de sua implantação, por ser uma cultura sensível a diversas pragas e doenças.

A cotonicultura é de grande relevância para o agronegócio brasileiro, sendo produzida em mais de quinze estados (OLIVEIRA et al., 2012). Os maiores produtores são: o estado de Mato Grosso que ocupa a primeira posição, com mais de 2,0 milhões de toneladas, seguido da Bahia com 567,9 mil, Goiás com 65,2 mil e Minas Gerais com 64,9 mil toneladas. A nível mundial, o Brasil ocupa a quinta posição, ficando atrás apenas da Índia, China, Estados Unidos e Paquistão. (COMPANHIA NACIONAL DE ABASTECIMENTO-CONAB, 2020).

O sucesso da cotonicultura depende de alguns fatores como: a obtenção de cultivares com boa qualidade física, fisiológica e sanitária, que proporcionem plântulas uniforme e vigorosas, capazes de se tornarem plantas adultas de excelente potencial produtivo, com aumento de produção por área plantada (LAUXEN et al., 2010). A diferença de temperatura, luz solar e a disponibilidade de água são fatores que podem influenciar na produtividade do algodão, no entanto, isso pode ser contornado pela época de plantio (WELL; STEWART, 2010).

Atualmente, existem diversas cultivares disponíveis no mercado, pesquisa a respeito desses materiais são necessárias para auxiliar o agricultor na escolha e posicionamento de materiais para cultivos (MORELLO et al., 2015). Deve-se dar preferência às cultivares adaptadas à região, época de semeadura, vigor de sementes, e condições fitossanitárias, bem com tolerância e resistência a doenças, buscando altas produtividades (PESKE et al., 2012).

A região Centro-Oeste vem se destacando no cultivo de algodão devido suas características climáticas favoráveis (BELTRÃO et al., 2011). Os solos do cerrado naturalmente possuem baixa fertilidade, sendo indispensável o uso de corretivos e fertilizantes e estudo do solo e manejo agronômico para promoverem um melhor potencial do algodoeiro (AQUINO et al., 2012).

Recentemente a cultura do algodão vem avançando em várias regiões do cerrado, assim como em Confresa-MT, porém, existem poucos trabalhos sobre a cultura do algodão nessa região. Dessa maneira, este trabalho teve como objetivou analisar o comportamento de cultivares de algodão submetidas às mesmas condições e avaliar adaptabilidade e produtividade 
das cultivares nessa região.

\section{Metodologia}

O ensaio foi instalado no campo experimental da empresa Xingu Pesquisa e Consultoria Agronômica Ltda-me, situada na margem da BR 158 KM 152 sob as coordenadas S1043' 48,2" e W0 51³5'42,3" no município de Confresa - MT, região nordeste do estado de Mato Grosso. A região apresenta média de 230 metros de altitude. De acordo como categorização de Köppen, apresenta verão chuvoso e inverno seco, enquadrando-se no clima tropical úmido (Aw).

Anteriormente a semeadura, realizou-se uma análise de solo (como ilustra a tabela 1), com o objetivo de suprir as necessidades nutricionais através da adubação.

Tabela 1. Resultado da análise química do solo.

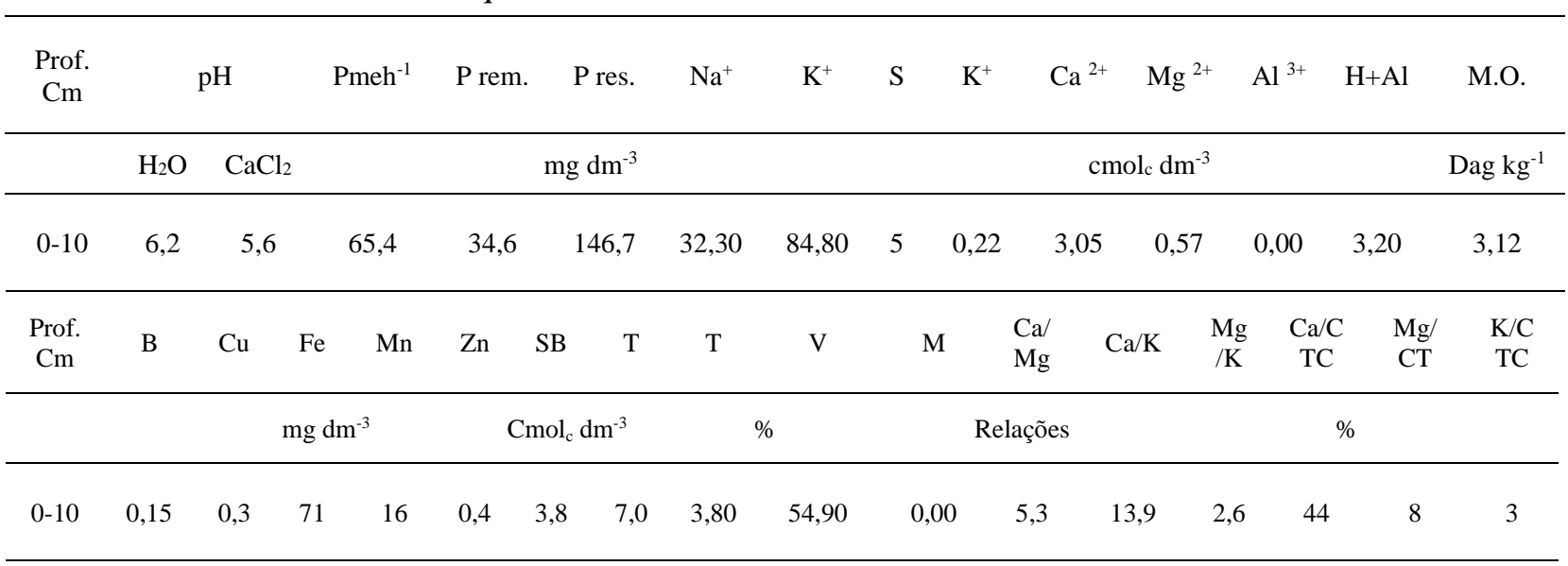

Extrator: P, K, Cu, Fe, Mn, Zn,Na = (Mehlich); Al, Ca, Mg = (KCl 1M); P-Resina = (Resina Trocadora de Íons $)$; M.O. $=(\mathrm{Na} 2 \mathrm{Cr} 2 \mathrm{O} 7.2 \mathrm{H} 2 \mathrm{O}+\mathrm{H} 2 \mathrm{SO} 4 ; \mathrm{S}=(\mathrm{Ca}(\mathrm{H} 2 \mathrm{PO} 4120,01 \mathrm{M}$.

A adubação de base foi realizada com $200 \mathrm{~kg}$ de Fosfato Monoamônico (MAP), contendo $20 \mathrm{~kg}$ de $\mathrm{N}$ e $100 \mathrm{~kg}$ de $\mathrm{P}_{2} \mathrm{O}_{5}$. A adubações de cobertura foi feita a lanço, utilizando $150 \mathrm{~kg}$. ha ${ }^{-1}$ de Potássio e $150 \mathrm{~kg}$. ha ${ }^{-1}$ de $\mathrm{N}$ em duas aplicações nos estágios fenológicos V5 e V8. A adubação foi uniforme na área, a fim de proporcionar as mesmas condições para todas as cultivares que foram semeadas.

Foi utilizado delineamento inteiramente casualizados (DIC), onde os tratamentos consistiram em dez cultivares dispostas uma ao lado da outra, com três repetições. foram utilizadas cinco cultivares IMA (2106 GL, 8405 GLT WS, 6801 B2RF, 5801 B2RF, 7501 WS) e cinco TMG (47 B2RF, $61 \mathrm{RF}, 62 \mathrm{RF}, 44 \mathrm{~B} 2 \mathrm{RF}, 81 \mathrm{WS}$ ). As parcelas experimentais eram constituídas de seis linhas com cinquenta metros de comprimento e espaçamento de 0,9 metros 
entre plantas, e distribuição de oito sementes por metro linear. Os tratamentos fitossanitários foram realizados observando recomendações descritas em na bula dos produtos de acordo com a necessidade em cada momento da cultura, como demonstrado na tabela 3 .

Tabela 3. Descrição de manejo fitossanitários planejado no experimento com cultivares de algodão em Confresa-MT.

\begin{tabular}{|c|c|c|c|}
\hline Dia & Atividade & Inseticida & Fungicida \\
\hline 06/03/19 & Aplicação Inseticida & Acetamiprido & - \\
\hline $15 / 03 / 19$ & Aplicação de inseticida & $\begin{array}{l}\text { Acetamiprido } \\
\text { Piriproxifem }\end{array}$ & - \\
\hline 25/03/19 & Aplicação inseticida+Fungicida & Piriproxifem & $\begin{array}{l}\text { Protioconazol + } \\
\text { Trifloxistrobina }\end{array}$ \\
\hline 01/04/19 & Aplicação inseticida+Fungicida & Abamectina & $\begin{array}{c}\text { fluxapiroxade } \\
+ \text { piraclostrobina } \\
\text { Oxicloreto de cobre }\end{array}$ \\
\hline 09/04/19 & Aplicação Inseticida + Fungicida & Abamectina & Hidróxido de Fentina \\
\hline $18 / 04 / 19$ & Aplicação Inseticida + Fungicida & $\begin{array}{c}\text { Abacmectina }+ \\
\text { Emamectina }\end{array}$ & $\begin{array}{c}\text { fluxapiroxade } \\
+ \text { piraclostrobina } \\
\text { Oxicloreto de cobre }\end{array}$ \\
\hline 24/04/19 & Aplicação regulador & - & - \\
\hline 25/04/19 & Aplicação Inseticida + Fungicida & $\begin{array}{c}\text { Abacmectina + } \\
\text { Emamectina }\end{array}$ & Hidróxido de Fentina \\
\hline $05 / 05 / 19$ & Aplicação Inseticida + Fungicida & $\begin{array}{c}\text { Abacmectina + } \\
\text { Emamectina }\end{array}$ & $\begin{array}{c}\text { fluxapiroxade } \\
+ \text { piraclostrobina } \\
\text { Clorotalonil }\end{array}$ \\
\hline
\end{tabular}

Adicionalmente aos tratos fitossanitários apresentados na tabela 3, foram aplicados regulador de crescimento Cloreto de Mepiquat na dose de $50 \mathrm{~mL}$. ha ${ }^{-1}$ nas datas de 18/03, 22/03, 27/03, 02/04, 07/04, 12/04, 17/04, 22/04, 27/04 e 02/05 para conter o avanço do crescimento vegetativo da cultura do algodoeiro.

Foram realizadas as avaliações de estande de plantas (população final), altura de planta, número de nós, número de abortos, número de capulhos e produtividade.

Ao final do experimento, os dados foram submetidos à análise de variância, no qual se utilizou o programa estatístico SISVAR, versão 4.0 (FERREIRA, 2000). Os dados coletados submetidos à análise de variância $(\mathrm{p}<0,5)$ e, quando significativas, as médias foram comparadas pelo teste Scott-Knott $(\mathrm{p}<0,5)$. 


\subsection{Cultivares}

\section{2.1.1. IMA 2106 GL}

Resistente ao glifosato e ao glufosinato de amônio. Sua semeadura é indicada após os primeiros quinze dias do mês de dezembro. A população de planta varia entre 100.000 a 120.000 plantas/ha. O ciclo da IMA 2106 GL é intermediário, apresentando de porte médio, peso de capulhos varia de 4,0 g a 4,8 g. Elevada exigência nutricional, com rendimento de fibra de 40,0 e 41,0\%, comprimento variando entre 30 a 31 mm (VILELA; BELOTI, 2015).

\section{2.1.2. IMA 8405 GLT WS}

Essa cultivar é indicada tanto para $1^{\mathrm{a}}$ safra quanto para $2^{\mathrm{a}}$ safra, apresentando ciclo tardio, é altamente responsiva a fertilidade do solo, exigência elevada de regulador de crescimento. Possui resistência moderada às diversas doenças do algodoeiro, como: bacteriose, doença azul, ramulária e ramulose, virose atípica e a nematoides, como: Meloidogyne incógnita (VILELA: BELOTI, 2015).

\section{2.1.3. IMA 6801 B2RF}

De acordo com os dados do Instituto Mato-Grossense do Algodão (IMA, 2019), a comercialização da cultivar IMA 6801 iniciou-se no ano de 2019. Nos 18 ensaios em diversas regiões do país avaliando a resistência dessa cultivar à diversas doenças, constatou-se resistência desta a mancha angular e doença azul, sendo suscetível ramulária, ramulose, murcha de Fusarium e viroses atípicas.

\section{2.1.4. IMA 5801 B2RF}

Cultivar resistente aos nematoides das galhas, ciclo médio precoce, planta de porte médio com capulhos pesando entre 5,0 a 5,6 g e, rendimento de fibra entre 37 a $39 \%$. Alta exigência em fertilidade de solo, sendo indicado a realização da aplicação de regulador de crescimento no início do ciclo (VILELA: BELOTI, 2015). Não é recomendado dessa cultivar em áreas de primeiro ano de cultivo, pois é altamente susceptível ao apodrecimento das maçãs (IMAMT, 2019).

\section{$5 \quad$ 2.1.5. IMA 7501 WS}

A cultivar IMA 7501 WS é considerada uma boa opção para o plantio de algodão safra 
na região Sul de Mato Grosso, assim como para a abertura de áreas de algodão segunda safra em todos os núcleos regionais do estado (IMAMT, 2018). Resistente as doenças bacteriose e a doença azul, considerada moderadamente resistente a ramulária e tolerante a nematoides.

\section{2.1.6. TMG $81 \mathrm{WS}$}

Conforme os resultados da Tropical Melhoramento e Genética (TMG, 2015), essa cultivar é considerada apta para solos de média fertilidade e tolerância a nematoide de galha. Essa cultivar apresenta ciclo tardio, com peso médio do capulho de 4,89 g. A exigência de regulador é alta, tendo que se atentar bastante no uso de reguladores, precisa-se de solos com alta fertilidade para expressar o seu maior potencial produtivo.

O plantio da cultivar no estado de Mato Grosso é indicado da segunda semana de dezembro, até a segunda semana de janeiro, devido ao fato de ser uma cultivar de ciclo longo, então deve-se adiantar a semeadura, o espaçamento indicado entre linhas é de 0,78 a 0,90 m.

\section{2.1.7. TMG 44 B2RF}

Essa cultivar apresenta o ciclo médio precoce com peso médio de capulho de 4,87 g e altamente exigente em fertilidade. A semeadura no estado de Mato Grosso é indicada para o final de dezembro até a primeira semana de fevereiro, e o espaçamento entre linhas indicado é de 0,76 a 0,90 m (TMG, 2020).

\section{2.1.8. TMG 47 B2RF}

É uma cultivar de porte baixo, apresentando pouca exigência no uso de regulador de crescimento, seu é ciclo médio tardio, espaçamento recomendado de 0,76 a 0,90 metro, com estande variando de 8 a 10 plantas por metro, com peso médio de capulho de 3,98 g. A exigência, quanto a fertilidade é alta, o rendimento de fibra chega a $43 \%$. Recomenda-se seu cultivo no estado de estado de Mato Grosso a partir da segunda quinzena de dezembro até a terceira semana de janeiro, uma janela mais curta que outras cultivares, devido ao ciclo longo (TMG, 2020).

\section{2.1.9. TMG $61 \mathrm{RF}$}

Cultivar de ciclo médio, resistente a bacteriose, doença azul e tolerante a ramulose. Exige alta fertilidade de solo, estande de 7 a 9 plantas por metro linear, recomendadas para região do estado de Mato Grosso, com espaçamento de 0,76 a 0,90 m, e com peso de médio de capulho de $4.50 \mathrm{~g}$ (TMG, 2020). 


\section{2.1.10. TMG 62 RF}

Considerada uma excelente opção para área de refúgio, apresenta características como, ciclo médio, estande de 7 a 9 plantas por metro linear, peso de médio de capulho de $5.5 \mathrm{~g}$. A exigência de regulador de crescimento é média, já a de fertilidade é alta. O rendimento da fibra é de $42.60 \%$, o posicionamento da cultivar para o estado de Mato Grosso é para o final de dezembro até final de janeiro, com espaçamento de 0,76 a 0,90 m (TMG, 2020).

\section{Resultados e Discussão}

A figura 6 apresenta os resultados da análise de variância da altura de planta, números de nós e produtividade. Para o número de capulhos e número de abortos, não houve diferença significativa entre as cultivares. Um dos principais problemas foi o alto índice de abortamento de estrutura reprodutivas. das cultivares avaliadas. As cultivares IMA 2106 GL e IMA 6801 B2RF demonstraram menor capacidade de crescimento.

Tabela 5 - Resumo da análise de variância nas variáveis: Estande, Altura de plantas, número de capulhos, número de abortos por planta, número de nós e produtividade em função das diferentes cultivares, em Confresa - MT.

\begin{tabular}{lccccccc}
\hline FV & \multicolumn{7}{c}{ Quadrado médio } \\
\hline & $\mathrm{G}$ & Estande & Altura & $\begin{array}{c}\mathrm{N}^{\mathbf{o}} \mathrm{de} \\
\text { capulho } \\
\mathrm{s}\end{array}$ & $\begin{array}{c}\mathrm{N}^{\mathrm{o}} \mathrm{de} \\
\text { aborto } \\
\mathrm{s}\end{array}$ & $\begin{array}{c}\mathrm{N}^{\mathbf{o}} \text { de } \\
\text { Nós }\end{array}$ & $\begin{array}{c}\text { Produtivid } \\
\text { ade }\end{array}$ \\
\hline Cultivares & 9 & $9.70^{* *}$ & $\begin{array}{c}505.04 * \\
*\end{array}$ & 685,92 & 29.78 & & $0.21^{* *}$ \\
Resíduo & 20 & 2.70 & 61.00 & 326.60 & 12.57 & 1.17 & 0.01 \\
C.V & & 9.25 & 4.84 & 15.82 & 13.94 & 4.35 & 8.17 \\
Média & & 17.76 & 161.43 & 114.23 & 25.43 & 24.83 & 1.02 \\
\hline * Significativo a 5\% de probabilidade, ** significativo a 1\%, pelo teste $\mathrm{F}$. & &
\end{tabular}

Inicialmente foi utilizada a mesma quantidade de sementes por metro linear, no entanto, o estande final foi variável (Tabela 6), sendo as cultivares TMG 81 WS, IMA 5801 B2RF e TMG 62 RF, as que se destacaram das demais cultivares, porém não se diferenciaram entre si.

Tabela 6 - Estande final de plantas de algodão em Confresa - MT, 2019.

Estande final de plantas por metro

\begin{tabular}{lll}
\hline Cultivares & Médias & Resultados dos Testes
\end{tabular}




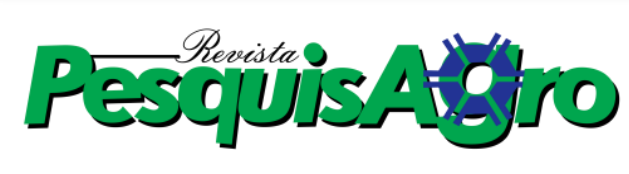

\begin{tabular}{lcc}
\hline TMG 81 WS & 10.333333 & $\mathrm{a}$ \\
IMA 5801 B2RF & 10.000000 & $\mathrm{a}$ \\
TMG 62 RF & 9.833333 & $\mathrm{a}$ \\
TMG 47 B2RF & 9.000000 & $\mathrm{~b}$ \\
IMA 7501 WS & 8.666667 & $\mathrm{~b}$ \\
TMG 44 B2RF & 8.666667 & $\mathrm{~b}$ \\
IMA 8405 GLT WS & 8.500000 & $\mathrm{~b}$ \\
IMA 6801 B2RF & 8.166665 & $\mathrm{~b}$ \\
IMA 2106 GL & 8.000000 & $\mathrm{~b}$ \\
TMG 61 RF & 7.66666 & $\mathrm{~b}$ \\
\hline
\end{tabular}

*Médias seguidas pela mesma letra minúscula na coluna não se diferenciam estatisticamente pelo Teste Scott Knott com 5\% de significância.

Conforme Martin (2006) o número de plantas por área possui atuação e influência no comportamento morfológico e fisiológico do algodoeiro.

Lacerda (2006) afirma que o número de plantas interfere diretamente na produtividade, que o estande ideal seria em função da fertilidade do solo, porte e crescimento dessa cultura, e destaca que no Brasil a população recomendada é de 8 a 15 plantas por metro em espaçamentos médios de 0,76 m entre linhas, ou em densidades de $0,90 \mathrm{~m}$ a 1,0 m entre linhas com uma população de 7 a 10 plantas por metro, ressalta-se que todas as cultivares estão de acordo com o apontamento do autor.

Silva et al. (2006) corrobora com o autor supracitado, sustentando que o arranjo da densidade de plantas pode favorecer a gestão da cultura do algodão e até mesmo ampliar a sua produtividade.

A Tabela 7, ilustra os resultados da média de altura de plantas, as cultivares IMA 2106 GL e IMA 6801 B2 RF, apresentaram menores médias, com valores de 142,33 cm e 137,33 centímetros respectivamente, essa altura está próxima aos parâmetros considerado ideal para a cultura do algodão (SILVA FILHO et al., 2017). A altura das plantas está correlacionada diretamente a sua arquitetura (espaçamento entre nós, número de nós) o que pode influenciar diretamente no quesito produtividade, além de facilitar a colheita mecanizada. Já as demais cultivares não se diferenciaram entre si. 
Tabela 7 - Média de altura de planta de algodoeiro em Confresa - MT, 2019.

\begin{tabular}{lcc}
\hline & Altura de Planta $(\mathbf{c m})$ & \\
\hline Cultivares & Médias & Resultados dos Testes \\
\hline IMA 7501 WS & 179.000000 & $\mathrm{a}$ \\
TMG 47 B2RF & 171.000000 & $\mathrm{a}$ \\
TMG 62 RF & 171.000000 & $\mathrm{a}$ \\
TMG 61 RF & 165.666667 & $\mathrm{a}$ \\
TMG 81 WS & 165,333333 & $\mathrm{a}$ \\
TMG 44 B2RF & 165.333333 & $\mathrm{a}$ \\
IMA 8405 GLT WS & 161.333333 & $\mathrm{a}$ \\
TMG 5801 B2RF & 156,000000 & $\mathrm{a}$ \\
IMA 2106 GL & 142.333333 & $\mathrm{~b}$ \\
IMA 6801 B2RF & 137,333333 & $\mathrm{~b}$ \\
\hline * Médias seguidas pela mesma letra minúscula na coluna não se diferenciam estatisticamente pelo Teste \\
Scott Knott com 5\% de significância.
\end{tabular}

Valores inferiores foram observados por Paiva (2019) que testando dez cultivares de algodão em Uberlândia - MG obtiveram média de altura na maturação variando entre 77,05 e 90,07 cm nas dez cultivares avaliadas. Tendo em vista que reguladores de crescimento não foram aplicados no momento certo, devido ao atraso na entrega dos produtos, as cultivares semeadas em Confresa obtiveram médias superiores as encontradas em Uberlândia. O intervalo de maturação das cultivares de algodão foram curtos em relação às encontradas neste trabalho. Segundo Beltrão (2011), o algodão é uma cultura que é favorecida pelas altas temperaturas, condição estas que estão presente no município onde foi conduzido o experimento, que de acordo com os dados coletados na Estação A918 - INMET (2014-2015), a temperatura média anual é de $24^{\circ} \mathrm{C}$, maior máxima $42^{\circ} \mathrm{C}$, e menor $4^{\circ} \mathrm{C}$, o que explica o maior crescimento das cultivares.

De acordo com Kaneko (2014) a altura ideal das plantas de algodão é de no máximo 1,30 m para que não prejudique a colheita mecanizada, pois alturas superiores a essas podem ocasionar tombamento e consequentemente serem amassadas pelo tráfego de máquinas na colheita (Silva et al., 2011). Os números obtidos no trabalho em Confresa - MT, indica que os valores deste trabalho em relação a variável altura de planta estão um pouco acima do desejado, devido ao atraso nas aplicações do regulador de crescimento.

Bogiani; Rosalem (2009) falam sobre a importância do uso dos reguladores de crescimento durante todo o ciclo da cultura do algodoeiro, para que as plantas não venham crescer demasiadamente, pois as plantas precisam apresentar um porte que varia de $130 \mathrm{~cm}$ a $150 \mathrm{~cm}$, para melhorar a eficiência de colheita, principalmente em regiões com clima e ambiente favorável, e pra fazer tais recomendações é importante se atentar ao modo de ação dos produtos, como o cloreto de mepiquat e cloreto de clormequat. 
Brandão et al. (2009) diz que a cultura do algodão possui crescimento inicial moroso, desenvolvendo rapidamente somente a partir de 25 a 30 dias após emergência sendo que mais de $50 \%$ de seus nutrientes são absorvidos depois desse período.

É apropriado salientar que a altura de planta é uma particularidade genética de cada cultivar, se diversificando, porém o uso de reguladores de crescimento utilizados auxilia a manter as médias de altura por plantas uniformes.

$\mathrm{Na}$ Tabela 8, que se refere a variável número de nós, constata-se significância, sendo a cultivar IMA 7501 WS com a maior produção de números de nós.

Tabela 8-Média de número de nós no algodoeiro em Confresa - MT, 2019.

\begin{tabular}{lcc}
\hline \multicolumn{3}{c}{ Números de nós } \\
\hline Cultivares & Médias & Resultados dos Testes \\
\hline IMA 7501 WS & 28,000000 & $\mathrm{a}$ \\
TMG 61 RF & 26,000000 & $\mathrm{~b}$ \\
IMA 8405 GLT WS & 26,000000 & $\mathrm{~b}$ \\
IMA 6801 B2RF & 25,333333 & $\mathrm{~b}$ \\
TMG 44 B2RF & 25,000000 & $\mathrm{~b}$ \\
TMG 81 WS & 24,666667 & $\mathrm{c}$ \\
IMA 2106 GL & 24,333333 & $\mathrm{c}$ \\
TMG 62 RF & 24,000000 & $\mathrm{c}$ \\
TMG 5801 B2RF & 23,666667 & $\mathrm{c}$ \\
TMG 47 B2RF & 21,333333 & $\mathrm{~d}$ \\
\hline * Médias seguidas pela mesma letra minúscula na coluna não se diferenciam estatisticamente pelo Teste &
\end{tabular}

Diferente desses resultados, Paiva (2019) que obteve uma média de números de nós de 15,2 para as 10 cultivares avaliadas, de programas de melhoramento genético do Brasil. Essa diferença no número de nós é devido a maior altura apresentada pelas plantas avaliadas no experimento em Confresa, devido ao atraso na chegada dos produtos e consequentemente em suas aplicações, as plantas cresceram e apresentaram maior número de nós.

Ferreira et al. (2015) afirmam que as cultivares de algodão de pequeno porte, com o número menor de nós e com ciclos menores se ajustam as exigências do cultivo no estado de Mato Grosso, o que facilita a introdução da cultura no cerrado brasileiro.

$\mathrm{Na}$ tabela 9 estão expostos os valores de produtividade expressos em arroba e quilogramas por hectare, onde pode-se analisar que a cultivar IMA 5801 B2RF foi a mais produtiva e a TMG $47 \mathrm{~B} 2 \mathrm{RF}$ apresentou-se menos produtiva. 
Tabela 9- Produtividade do algodoeiro semeado no município de Confresa - MT, 2019.

\begin{tabular}{llc}
\hline & \multicolumn{1}{c}{ Produtividade } & \\
\hline Cultivares & Médias @ / $(\mathrm{Kg})$ & Resultados dos Testes \\
\hline TMG 5801 B2RF & $292,96 / 4.394,40$ & $\mathrm{a}$ \\
TMG 62 RF & $229,81 / 3.447,15$ & $\mathrm{~b}$ \\
IMA 6801 B2RF & $218,70 / 3.280,50$ & $\mathrm{~b}$ \\
IMA 7501 WS & $196,29 / 2.944,35$ & $\mathrm{~b}$ \\
IMA 8405 GLT WS & $181,29 / 2.719,35$ & $\mathrm{~b}$ \\
TMG 44 B2RF & $178,14 / 2.672,10$ & $\mathrm{c}$ \\
TMG 81 WS & $181,11 / 2.716,65$ & $\mathrm{c}$ \\
IMA 2106 GL & $137,46 / 2.061,90$ & $\mathrm{~d}$ \\
TMG 61 RF & $137,40 / 2.061,00$ & $\mathrm{~d}$ \\
TMG 47 B2RF & $135,55 / 2.033,25$ & $\mathrm{~d}$ \\
\hline * Médias seguidas pela mesma letra minúscula na coluna não se diferenciam estatisticamente pelo Teste \\
Scott Knott com 5\% de significância.
\end{tabular}

O estudo sobre produtividade de cultivares do algodoeiro por Hoogerheide et al., (2007) avaliou oito genótipos de algodoeiro herbáceo, sendo três linhagens e cinco cultivares, esse estudo foi conduzido em 11 cidades no estado de Mato Grosso, entre elas Lucas do Rio Verde, Primavera do Leste e Sorriso, locais estes onde já é consolidada a cotonicultura, com total de 12 experimentos, os autores verificaram valores de 326,13@ até 362,73@, valores que são superiores aos encontrado no experimento em Confresa. Por serem regiões onde o cultivo de algodão já está consolidado há algum tempo, se tem uma maior adaptabilidade dos materiais comerciais disponíveis, esse fator de adaptação pode ter feito com que o estudo de Hoogerheide et al., (2007) tenha encontrado valores superiores ao de 292,86@ .

Alguns outros fatores a serem observados durante o estudo, e que possa ter influenciado a produtividade do estudo em Confresa, é o atraso na aplicação do regulador de crescimento (Cloreto de Mepiquat). $\mathrm{O}$ atraso ocorrido devido à demora no envio do produto, ocasionou maior crescimento das plantas, fazendo com que elas ultrapassassem os padrões desejado (relação entre altura e espaço entre nós).

Já Anselmo et al. (2011), durante um trabalho realizado em Chapadão do Sul - MS, encontrou resultados mais próximos dos que se obteve neste trabalho, a variação de produtividade encontrada por ele variou de 77,53@ a 243,28@, podendo variar conforme a época de plantio.

As médias de produção obtidas por Anselmo et al., (2011) não superaram as do trabalho conduzido em Confresa, um dos fatores a serem considerados são: baixas temperaturas encontradas em Chapadão do Sul - MS e os genótipos utilizados, uma vez que os atuais podem ser considerados mais produtivos. A cultura do algodão requer dias bastante ensolarados, com temperatura média mensal superior a $20^{\circ} \mathrm{C}$, ou seja, a região de Confresa consegue oferecer 
condições mais favoráveis ao desenvolvimento do algodão, segundo Beltrão (2006).

No estudo conduzido por Rodrigues et al. (2019) município de Presidente Bernardes SP, na safra 2018/2019, em solo de textura arenosa, que dentre as cultivares avaliadas a IMA $5801 \mathrm{~B} 2 \mathrm{RF}$, foi uma das que obtiveram menor produtividade. Isso pode ser devido as condições edafoclimáticas, pois se trata de regiões diferentes. No trabalho conduzido em Confresa, Mato Grosso, a cultivar TMG 5801 B2RF foi a que mais se destacou em produtividade, atingindo cerca de 4.394,40 kg rendimento de $1.000 \mathrm{~kg}$ com relação a segunda cultivar com melhor produtividade da variedade TMG $62 \mathrm{RF}$.

\section{Considerações}

Houve variabilidade genética para as variáveis de estande, altura de plantas, número de nós e produtividade. A cultivar IMA 5801 B2RF, nas condições do experimento foi a que demonstrou maior produtividade e adaptação as condições edafoclimáticas da região em relação as demais cultivares. Vale ressaltar que são necessários novos estudos para validação edafoclimática da região para produção de algodão.

\section{Referências}

ANSELMO J. L.; HOLANDA H. V.; ALVES L. A.; LOURENÇO P. H. F. N.; LEONEL T. Z., MAGALHÃES H. J. S.; RICIERI A. D. Comportamento de cultivares de algodão em função da época de semeadura no sistema adensado, na região dos chapadões. $8^{\circ}$ Congresso Brasileiro de Algodão \& I Cotton Expo 2011, São Paulo, SP - 2011

AQUINO L. A.; AQUINO, R. F. B. A.; SILVA, T. C.; SANTOS, D. F.; BERGER, P. G. Aplicação do fósforo e da irrigação na absorção e exportação de nutrientes pelo algodoeiro. Engenharia Agrícola Ambiental, Campina Grande, v. 16, n. 4, p. 355-361, 2012.

BELTRÃO, N. E. Clima regula produção e qualidade da fibra do algodoeiro. Visão agrícola, n. 6, 2006. Disponível em: <https://www.esalq.usp.br/visaoagricola/sites/default/files/va06manejo01.pdf $>$. Acessado em: 05 ago. 2020

BELTRÃO, N. E. de M. et al. Zoneamento agroclimático do algodoeiro no cerrado brasileiro. In: FREIRE, E. C. Algodão no cerrado do Brasil. Aparecida de Goiânia: ABRAPA. 2011. p.239-256.

BOGIANI, J.C.; ROSOLEM, C.A. Sensibilidade de cultivares de algodoeiro ao cloreto de mepiquat. Pesquisa Agropecuária Tropical, v.44, n.10, pp. 1246-1253. 2009. Disponível em: <http://seer.sct.embrapa.br/index.php/pab/article/view/2078.> Acesso em: 07 jul 2020.

BRANDÃO, Z. N.; SOFIATTI, V.; FERREIRA, G. B.; LIMA, R. L. S.; BELTRÃO, N. 
D.M.; SILVA, B. D. Predição da adubação nitrogenada através da utilização do índice SPAD para o algodoeiro no semi-árido. Engenharia Ambiental, v. 6, n. 3, p. 368 - 382, 2009.

CONAB. Companhia Nacional de Abastecimento. Cronograma de divulgação de safras.

Disponivel em: <:https://www.conab.gov.br/info-agro/safras/graos/boletim-da-safra-degraos $>$ Acesso em 02/08/2020

EMBRAPA. Empresa Brasileira de Pesquisa Agropecuária. Algodão: o produtor pergunta, a Embrapa responde. Brasília, DF: Embrapa Informação Tecnológica, 2004. 265p. (Coleção 500 perguntas, 500 respostas). ISBN 85-7383-278-9.

FERREIRA, A. C. B. et al. Épocas de semeadura, cultivares e densidade de plantas para algodão adensado em segunda safra. Pesquisa Agropecuária Tropical, v. 45, n. 4, p. 397 $405,2015$.

FERREIRA, D. F. Análises estatísticas por meio do SISVAR para Windows versão 4.0. In: 45 a . Reunião Anual da Região Brasileira da Sociedade Internacional de Biometria. 2000. São Carlos. Anais... São Carlos: Universidade Federal de São Carlos, 2000. Disponível em: <http://www.ppgest.ufscar.br/documentos/rt/rt27.pdf.>Acesso em: 16 fev. 2020.

HOOGERHEIDE, E. S. S.; FARIAS, F. J. C.; VENCOVSKY, R.; FREIRE, E. C. Estabilidade fenotípica de genótipos de algodoeiro no Estado do Mato Grosso. Pesquisa Agropecuária Brasileira, v.42, n.5, p.695-698, maio 2007.

IMAMT. Instituto Mato-grossense do Algodão. Boletim de Pesquisas e Doenças. O algodão geneticamente modificado para resistência a pragas: Eficiência e medidas para o manejo da resistência. n. 4. Cuiabá (MT). Março de 2019. p. 288. ISBN: 978-85-66457-15-5. Disponível em: <https://imamt.org.br/wp-content/uploads/2019/05/boletim-pesquisaresistencia-2019-web.pdf.> Acesso em: 21 fev. 2020.

IMAMT. Instituto Mato-grossense do Algodão. CIRCULAR TÉCNICA. Reação de cultivares de algodoeiro a doenças e nematoides, safra 2018/19. no. 43. agosto de 2019. Disponível em: <https://imamt.org.br/wp-content/uploads/2019/09/circular-tecnica-edicao43bxok.pdf. $>$ Acesso em: 22 fev. 2020.

KANEKO, F. H.; LEAL, A. J. F.; DIAS, A. R.; ANSELMO, J. L.; BUZETTI, S.; DAL BEM, E. A.; GITTI, D. C.; NASCIMENTO, V. Resposta do algodoeiro em cultivo adensado a doses de nitrogênio, fósforo e potássio. Agrarian, v. 7, n. 25, p. 382-389, jul. 2014. Disponível em: $\langle$ http://ojs.ufgd.edu.br/index.php/agrarian/article/view/2618>. Acesso em: 31 de jul. 2020.

LACERDA, A. L. S. Efeito de população de plantas nas características agronômicas na cultura do algodão. 2006. Disponível em: <http://www.infobibos.com/Artigos/2006_3/algodao/index.htm>. Acesso em: 15 jul. 2020.

LAUXEN, L. R.; VILLELA, F. A.; SOARES, R. C. Desempenho de sementes tratadas com tiametoxan. Revista Brasileira de Sementes, v. 32, n. 3 p. 061-068, 2010.

MARTIN, J. Avanços da pesquisa sobre algodão ultra-adensado. In: Algodão - Pesquisas e resultados para o campo. Facual Cuiabá, 2006. p. 94-119. 
MORELLO, C. L.; PEDROSA, M. B.; SUASSUNA, N. D.; FARIAS, F. J. C.; SILVA FILHO, J. L.; PERINA, F. J.; FREIRE, E. C.; ALENCAR, A. R.; TAVARES, J. A.; OLIVEIRA, W. P. Desempenho de Cultivares de Algodoeiro no Cerrado do Estado da Bahia, Safra 2013/2014. EMBRAPA algodão. Campina Grande. 2015.

OLIVEIRA, F. A.; MEDEIROS, J. F.; OLIVEIRA, F. R. A.; FREIRE, A. G.; SOARES, L. C. S. Produção do algodoeiro em função da salinidade e tratamento de sementes com regulador de crescimento. Ciência Agronômica, Fortaleza, v.43, n.2, p.279-287, 2012.

PAIVA, T. S. Há divergência genética entre genótipos de algodoeiro transgênico e convencionais? 2019, 21 f, Trabalho de Conclusão de curso (Graduação em Agronomia) Universidade Federal de Uberlândia, Uberlândia - MG, 2019.

PESKE, S. T.; VILLELA, F. A.; MENEGHELO, G. Produção de sementes. Fundamentos Científicos e Tecnológicos. $3^{\circ}$ ed. ver. eampl. Pelotas: Ed. Universitária/UFPel, 2012, 564p.

RODRIGUES, D. R. SILVA; G. R. A. BALTAZAR; G. O. C. CORDEIRO; C. F. dos S. ECHER, F. R. Produtividade e qualidade da fibra de cultivares de algodão no oeste de São Paulo. In: Encontro Nacional de Ensino, Pesquisa e Extensão - ENEPE, 2019. Anais... Presidente Prudente- SP. ISSN: 1677-6321. p. 1771.

SILVA FILHO, J. L. et al. Avaliação de cultivares de algodoeiro no Cerrado da Bahia, safra 2015/2016. Campina Grande: Embrapa Algodão, 2017. 14p. (Documentos, 269).

SILVA, A. V. et al. Crescimento e desenvolvimento do algodoeiro em diferentes configurações de semeadura. Bragantia, Campinas, v. 65, n. 3, p. 407-411, 2006. Disponível em: 〈https://www.scielo.br/pdf/brag/v65n3/a06v65n3.pdf.> Acesso em: 07 jul 2020.

SILVA, R. P.; FERREIRA, I. C.; CASSIA, M. T. Perdas na colheita mecanizada de algodão. Scientia Agropecuaria, v. 2, n. 1, p. 7-12, 2011.

TMG. Tropical Melhoramento e Genética. Cultivares de algodão 2014/2015. Disponível em: <http://www.tmg.agr.br/files/pdf/TMG-Cultivares_de_Algodao_2014-2015.pdf>. Acesso em: 30 nov. 2020.

TMG. Tropical Melhoramento e Genética. Cultivares de Algodão. Disponível em: <http://www.tmg.agr.br/ptbr/cultivares/algodao>. Acesso em: 30 nov. 2020.

VILELA, P.M.C.A; BELOT, J. L. Variedade comerciais e pré-comerciais de algodão para o Mato Grosso. Circular técnica IMAmt, n²2, 2015. 